\title{
Genetic analysis of peroxisome proliferator-activated receptor $\gamma 1$ splice variants in human colorectal cell lines
}

\author{
CATHY FIATTE $^{1}$, CÉCILE HUIN ${ }^{1}$, ISABELLE BERTIN ${ }^{1}$, THÉCLA LESUFFLEUR ${ }^{2}$, ARNAUD PLUVINET ${ }^{1}$, \\ NADèGE TOUCHE ${ }^{1}$, FRANÇOIS PLÉNAT ${ }^{3}$, MICHEL DAUÇA ${ }^{1}$, LIONEL DOMENJOUD ${ }^{1}$ and HERVÉ SCHOHN ${ }^{1}$ \\ ${ }^{1}$ EA 3446 Proliférateurs de Peroxysomes, IFR 111, Laboratoire de Biologie Cellulaire du Développement, Faculté des \\ Sciences et Techniques, BP239, 54506 Vandoeuvre les Nancy Cedex; ${ }^{2}$ INSERM U763,Université Paris VII, \\ UFR Médical Denis Diderot, Hôpital Robert Debré, 48 Boulevard Sérurier, 75019 Paris; \\ ${ }^{3}$ EA 4001, Laboratoire de Radiopentialisation de la Préclinique à la Clinique, \\ Faculté de Médecine, BP189, 54505 Vandoeuvre les Nancy Cedex, France
}

Received June 19, 2006; Accepted August 7, 2006

\begin{abstract}
Peroxisome proliferator-activated receptor $\gamma$ $(\operatorname{PPAR} \gamma)$ is a member of the nuclear hormone receptor family. In colon, this transcription factor is involved in differentiation of absorptive cells. PPAR $\gamma$ participates also in colon carcinogenesis and cancer progression. Two isoforms, namely PPAR $\gamma 1$ and PPAR $\gamma 2$, have been described. Recently, new PPAR $\gamma 1$ transcripts whose translation raises PPAR $\gamma 1$ protein have been characterised. They differ from each other by combination of untranslated exons localised in the 5' UTR of the PPARG gene. Here, we studied whether such a diversity of PPAR $\gamma$ transcripts occurs in human colon cell models. Based on bioinformatic analysis, putative untranslated exons were identified in the human PPARG gene. By RT-PCR analysis, we have demonstrated that several of these untranslated exons are included in PPAR $\gamma$ transcripts from colon-derived cell lines or in those derived from other tissue. Using HT-29 cells, changes in PPAR $\gamma 1$ mRNA levels were observed after treatment with PPAR $\gamma$ agonists such as pioglitazone and troglitazone. These modifications correlated with particular PPAR $\gamma$ transcripts excluding the untranslated exon A2. HT-29 cells treatment with actinomycin D or cycloheximide showed that the presence of PPAR $\gamma$ mRNA including exon A2 was dependent on de novo protein synthesis. We concluded that diverse PPAR $\gamma 1$ mRNA exist in
\end{abstract}

Correspondence to: Dr Hervé Schohn, EA3446, Laboratoire de Biologie Cellulaire du Développement, Faculté des Sciences et Techniques, BP239, 54506 Vandoeuvre les Nancy Cedex, France

E-mail: herve.schohn@scbiol.uhp-nancy.fr

Abbreviations: PPAR, peroxisome proliferator-activated receptor; $E S T$, expressed sequence tagged; GAPDH, glyceraldehyde 3phosphate dehydrogenase

Key words: peroxisome proliferator-activated receptor $\gamma$, human colorectal cancer, colon differentiation, splicing colorectal cells. Levels of PPAR $\gamma 1$ transcript varied according to the phenotype of colon cell model used. We suggest that regulation of PPAR $\gamma 1$ mRNA levels could be dependent in part on the composition of untranslated exon(s) in the $5^{\prime}$ UTR of PPAR $\gamma 1$ mRNA.

\section{Introduction}

Peroxisome proliferator activated receptors (PPAR) belong to the nuclear hormone receptor superfamily (1). There are three isotypes named PPAR $\alpha, \operatorname{PPAR} \beta / \delta$ and PPAR $\gamma(2)$. These nuclear receptors act as heterodimers with the 9-cis retinoic acid receptor and bind to a specific DNA sequence, the peroxisome proliferator response element, a direct repeat of the 5'-AGGTCA-3' sequence spaced by one base $(3,4)$. After ligand activation, the heterodimer complex regulates the transcription of specific genes involved in several physiological functions (2). In colon, PPAR $\gamma$ is implicated in differentiation of absorptive cells (5), in carcinogenesis or tumour progression even though contradictory results have been obtained in murine and human models (6).

The PPAR $\gamma$ gene is localised to chromosome 3 , band 3 p25 (7). The open reading frame consists of exons E1-E6 which encode the different domains of the protein. In human, two PPAR $\gamma$ isoforms have been identified and referred to as PPAR $\gamma 1$ and PPAR $\gamma 2(7,8)$. PPAR $\gamma 2$ differs from PPAR $\gamma 1$ by an additional 28 amino acid NH2-terminal sequence (8). The 5' UTR region of PPAR $\gamma$ transcripts, raising PPAR $\gamma 1$ and -2 proteins, is highly variable and three exons termed A1, A2 and B have been described $(9,10)$. Due to different promoter usage and alternative splicing, two other PPAR $\gamma$ transcripts have been identified and they have been referred to as PPAR $\gamma 3$ and $-\gamma 4(10,11)$. PPAR $\gamma 1$ mRNA consists of A1-A2-E1-6 exons, whereas PPAR $\gamma 3$ mRNA is composed only of A2-E1-6 exons. Both the exons A1 and A2 are not translated. The PPAR $\gamma 4$ mRNA has a transcription initiation site at the boundary of exon E1 (at position -29 upstream of the start point of exon E1) (11). All these PPAR $\gamma$ transcripts generate the same protein PPAR $\gamma 1$. Other untranslated exons 
have also been identified in the 5' UTR of PPAR $\gamma$ mRNA in mouse (12), in monkey (13) and recently in normal human mammary epithelial and breast cancer cells (14). Wang et al demonstrated the presence of multiple transcription start sites leading to different PPAR $\gamma 1$ transcripts observed in mammary epithelial cells and breast cancers cells (14). The different promoters are thought to mediate specific PPAR $\gamma 1$ transcript expression in normal and tumoral tissues. In monkey macrophage and human macrophage-derived cell lines, Zhou et al (13) and Chen et al (15) respectively showed the presence of the so-called untranslated exon $\mathrm{C}$ and exon D in addition to the previously identified exons A1, A2 and B. Promoter usage and alternative splicing have raised seven PPAR $\gamma$ transcripts referred to as PPAR $\gamma 1-7$.

Due to the complexity of the PPAR $\gamma$ gene, we postulated that in colon cell models the regulation of PPARG gene expression could be the result of multiple promoter usage which in turn generates other transcripts encoding the protein PPAR $\gamma 1$ than the already described PPAR $\gamma 1,3$ or 4 mRNA. Many studies over the last 20 years have reported cancer-specific alternative splicing in the absence of genomic mutations (16). As well as being associated with cancer, the nature of the alternative gene products is usually consistent with an active role in cancer. Therefore, the alternative splicing process itself is a potential target for gene therapy. Using RT-PCR semi-quantification carried out with polyA ${ }^{+}$RNA from human colon cells and 5' extension primer experiments, we have demonstrated the presence of different PPAR $\gamma 1$ transcripts. Treatment of HT-29 cell line, a colon tumour cell model, with PPAR $\gamma$ agonists, actinomycin D or cycloheximide suggested that the variation in PPAR $\gamma$ mRNA levels could depend on the nature of PPAR $\gamma$ mRNA in colon cell model.

\section{Materials and methods}

Reagents. Dulbecco's modified Eagle's minimum medium (DMEM), trypsin/EDTA solution, fetal calf serum (FCS), non-essential amino acids solution, and Dulbecco's sodium phosphate buffer (DPBS) were purchased from Eurobio (Les Ulis, France). Taq polymerase, RNAsin, reverse transcriptase (M-MLV) and primers were obtained from Invitrogen Corporation (Paisley, Scotland). Restriction enzymes and protease inhibitor ready-made solution were from Sigma Corporation (St. Louis, MO, USA). BM Chemiluminescence revelation kit was from Roche (Mannheim, Germany). Commercial polyclonal rabbit antibodies against PPAR $\gamma$ were from Cayman (Tallin, Estonia). Polyclonal rabbit antibodies against $\beta$-actin were purchased from Sigma. Polyclonal rabbit antibodies against catalase were prepared and characterized as described before (17). Troglitazone was purchased from Cayman; pioglitazone was a gift from Tadeka Chemicals Industries Ltd. (Osaka, Japan). Other reagents were of analytical grade.

Cell culture. HT-29, Caco-2 cell lines were obtained from M. Rousset (INSERM U505, Paris, France). The HCT116 cell line was a gift of J.N. Freund (INSERM U682, Strasbourg, France). SW620 and MRC5 cell lines were obtained from N. Martinet (INSERM 555, Nancy, France). Vero and L293 cell lines were a gift of J.L. Goergen (INPL, Nancy, France).
A549 cells were obtained from N. Frossard (EA 3771, Strasbourg, France). HepG2, THLE, MCF-7, HeLa cells are part of the laboratory cell-line collection. Cells, except Caco-2 cells, were cultured in DMEM-25 mM glucose containing $10 \%(\mathrm{v} / \mathrm{v})$ heat-inactivated $\left(30 \mathrm{~min}\right.$ at $\left.56^{\circ} \mathrm{C}\right) \mathrm{FCS}$ and $2 \mathrm{mM}$ L-glutamine, and they were seeded at a concentration of $10^{5}$ cells $/ \mathrm{ml}$. Caco- 2 cells were cultured in the same medium containing $20 \%(\mathrm{v} / \mathrm{v})$ heat-inactivated FCS and $1 \%(\mathrm{v} / \mathrm{v})$ non-essential amino acids. Seeding was $6 \times 10^{4}$ cells $/ \mathrm{ml}$. All cells were grown in a $5 \% \mathrm{CO}_{2}$ humidified atmosphere. Medium was changed daily, $48 \mathrm{~h}$ after seeding. After 5 and 15 days of culture, cell layers were washed twice with cold-DPBS for 5 min. Cell layers were frozen at $-80^{\circ} \mathrm{C}$ until RNA extraction or cell homogenate preparation.

Cell treatments. Agonist treatment was carried out $48 \mathrm{~h}$ after HT-29 cell seeding for five days. Medium containing 1 or $10 \mu \mathrm{M}$ troglitazone or pioglitazone and $1 \mu \mathrm{M}$ 9-cis retinoic acid was changed daily. Cell layers were then washed three times with cold DPBS and stored at $-80^{\circ} \mathrm{C}$. HT-29 cells were assessed after two and five days for each treatment by using Trypan blue staining at least four times. Results are expressed at mean \pm SD. Five and 15-day-old HT-29 cells were treated in the presence of 1 or $10 \mu \mathrm{g} / \mathrm{ml}$ cycloheximide or 1 and $10 \mu \mathrm{M}$ actinomycin D for $24 \mathrm{~h}$. Thereafter, cell layers were washed twice with cold-DPBS, and stored at $-80^{\circ} \mathrm{C}$ until total RNA extraction.

RT-PCR analysis and semi-quantification of PPAR transcripts. Total RNA was phenol/chloroform extracted (18). PolyA $^{+}$RNAs were purified on oligo dT cellulose according to standard protocol (19). cDNAs were obtained by reverse transcription reaction according to standard protocol with M-MLV reverse transcriptase $(200 \mathrm{U})$ and $1 \mu \mathrm{g}$ of total or polyA $^{+}$RNA. cDNA amplification was carried out in $20 \mathrm{mM}$ Tris- $\mathrm{HCl}$ (pH 8.4) buffer containing $50 \mathrm{mM} \mathrm{KCl}, 1.5 \mathrm{mM}$ $\mathrm{MgCl}_{2}, 5 \mathrm{U}$ of RNAsin, $0.2 \mathrm{mM}$ dXTP, $0.4 \mu \mathrm{M}$ each selected sense and antisense primers, $2 \mu 1$ of reverse transcription sample and $2.5 \mathrm{U}$ of $\mathrm{Taq}$ polymerase for 35 cycles $\left(95^{\circ} \mathrm{C}\right.$, $30 \mathrm{sec}$; annealing temperature at $\mathrm{Tm}$ of the primers, $30 \mathrm{sec}$; $72^{\circ} \mathrm{C}, 30 \mathrm{sec}$ ) followed by an extension step at $72^{\circ} \mathrm{C}$ for $5 \mathrm{~min}$. Primers used in this study are listed in Table I. GAPDH was used as an internal control. Amplicons were analysed on a $2 \%(\mathrm{p} / \mathrm{v})$ TBE-agarose gel. The bands obtained were quantified (Gel Doc, Bio-Rad, Hercules, USA). Results are expressed as the ratio (PPAR $\gamma$ isoform human $\left./ \mathrm{GAPDH}_{\text {human }}\right)$ in arbitrary units. HinfI restriction enzyme which specific site is present only in exon A2 was used to verify the presence of exon A2 in amplicons obtained with primer sense A0, A1 or A5 and antisense primer E1. All PCR-products described here were cloned in pBlueScript plasmid and sequenced (INRA, Champenoux, France). We did not find any difference in sequence with those described on the UCSC Genome site. Total RNA from SW480, HCT EB and LS174T cells were prepared by T.L. as decribed above.

5'-Primer extension. The primer extension was carried out according to Domenjoud et al (20) starting with $4 \mu \mathrm{g}$ of polyA $^{+}$RNAs purified from HT-29 cells. Primers used are listed in Table I. 5' end primer labeling was carried out with 
Table I. Sequences of primers used in this study.

\begin{tabular}{|c|c|c|c|}
\hline Exon & Sequence primer $\left(5^{\prime}-3^{\prime}\right)$ & $\begin{array}{l}\text { Genomic localisation } \\
\text { on PPARG gene }\end{array}$ & $\begin{array}{l}\text { Length } \\
\text { (bp) }\end{array}$ \\
\hline
\end{tabular}

Primers used in RT-PCR experiments

A

A0

A1

A4

A5

A3

A2

C

E1 $a^{a}$

$\mathrm{E} 1 b^{\mathrm{b}}$

E4

E6

GAPDH antisense

GAPDH sense

ACATCTTGGGAAGACGGCCT
TTGGGTCGGCCTCGAGGACA
GTTAGGCTCCCAGGAGGAGTGGTCA
CTCTACCTTTAGACCATTCTGCAG
GCAAGAAGGAGATGACATATACTTAAG
CTTCGTGAGGGGTGTGCTG
GAAAGAAGCCAACACTAAACCAC
TTCAGGATGATTCTTGTCTCTGGA
GGGCCAGAATGGCATCTCTGTG
TGTGGAGTAGAAATGCTGGAGAAG
TCATGCTTGTGAAGGATGCAAGG
TCCAGTGCATTGAACTTCACAGC
GCTGTGATGGCATGGACTGTGGTCAT
GACCCCTTCATTGACCTCAACTACATG

ACATCTTGGGAAGACGGCCT

GTTAGGCTCCCAGGAGGAGTGGTCA

CTCTACCTTTAGACCATTCTGCAG

CTTCGTGAGGGGTGTGCTG

GAAAGAAGCCAACACTAAACCAC

TTCAGGATGATTCTTGTCTCTGGA

TGTGGAGTAGAAATGCTGGAGAAG

TCATGCTTGTGAAGGATGCAAGG

GCTGTGATGGCATGGACTGTGGTCAT

GACCCCTTCATTGACCTCAACTACATG

Primers used in 5 ' primer

extension procedure

$\begin{array}{ll}\text { A1 } & \text { GTTAGGCTCCCAGGAGGAGTGGTCA } \\ \text { A2 } & \text { GAGAAAATGGCCTTGTTGTATATTTG } \\ \text { A5 } & \text { CTTAAGTATATGTCATCTCCTTCTTGC } \\ \text { E1 } & \text { GGGCCAGAATGGCATCTCTGTG }\end{array}$

$\begin{array}{lll}12303981-12304000 & 20 & 50 \\ 12304467-12304486 & 20 & 54 \\ 12305390-12305416 & 25 & 54 \\ 12322341-12322364 & 24 & 50 \\ 12325334-12325360 & 27 & 50 \\ 12328321-12328338 & 19 & 50 \\ 12328883-12328905 & 23 & 48 \\ 12388353-12388376 & 24 & 49 \\ 12396219-12396240 & 22 & 53 \\ 12396327-12396350 & 24 & 51 \\ 12397969-12397991 & 23 & 60 \\ 12433578-12433600 & 23 & 60 \\ 6517010-6517033 & 26 & 60 \\ 6515994-6516020 & 27 & 60\end{array}$

\begin{tabular}{lll}
$12305366-12305390$ & 25 & 58 \\
$12328905-12328930$ & 26 & 48 \\
$12325334-12325360$ & 27 & 50 \\
$12396219-12396240$ & 22 & 53 \\
\hline
\end{tabular}

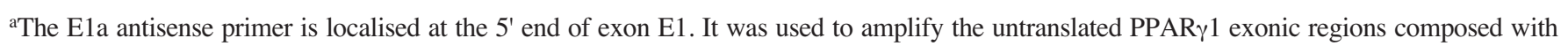
combined exons A1-A2, A5-A2 and A2 or A1 alone. ${ }^{\mathrm{b}}$ The E1b antisense primer is localised at the 3' end of exon E1. It was used to amplify the untranslated PPAR $\gamma 1$ exonic regions composed with combined exons A0-A2 or A0 alone.

${ }^{32} \mathrm{P}[\gamma]$-ATP using a labelling kit purchased from AmershamBiosciences (Orsay, France). Lengths of extension products were estimated in 5\% acrylamide/7 $\mathrm{M}$ urea gel prepared in TBE buffer.

Western blotting. Cell homogenates were prepared in freshly made extraction buffer according to Mansen et al (21). Protein $(50 \mu \mathrm{g})$ was resolved in $10 \%$ SDS-PAGE (22). Proteins were transferred onto PVDF membranes (23) and they were further proceeded for chemiluminescence detection according to the manufacturer's protocol. Dilution of the first antibody solution was 1:1,000 for polyclonal rabbit antibodies directed against PPAR $\gamma, 1: 20,000$ for polyclonal rabbit antibodies against $\beta$-actin, and 1:1,000 for polyclonal rabbit antibodies against catalase.

Statistics. All the statistics were computed using SPSS v11.5 software (SPSS Inc., Chicago, IL, USA). For the comparison of the variation of PPAR $\gamma$ transcript contents along cell culture duration, one way ANOVA was performed with Bonferroni post-hoc test for the multiple comparisons. Differences were considered significant at $\mathrm{P}<0.05$.

\section{Results}

Untranslated exons mapping on the PPARG gene. We first compiled the representative sequences of all spliced EST present in the data bank resources (Table II). In order to map putative and known untranslated exons of the PPARG gene, we looked for: a) cryptic splice sites as 5'-aggu-3' and 5'-agg-3'; b) intronic polypyrimidine sequences between a putative acceptor splice site and an A-branch site were localised in order to define the boundaries of internal exon; c) the presence of a putative Inr element was investigated in the genomic region upstream of each known or putative first exon. In addition to the known exons namely A, A0, A1, A2 and B, we found two additional exons A4 and A5 (Fig. 1b). No amplification product was obtained when RT-PCR was carried out with primers designed in exon A or A4 and E1, neither in colon normal-matched and tumour sample, nor in colon adenocarcinoma-derived cell lines (data not shown). Zhou et al (13) have suggested that exon C and D identified in monkey macrophages may exist in the human PPARG gene. Sequence alignments demonstrated that $<50 \%$ similarity exists between the sequence of exon D from monkey 
Table II. Selected human EST used to map the untranslated exons on the PPARG gene.

\begin{tabular}{lllc}
\hline EST & \multicolumn{1}{c}{ cDNA bank } & \multicolumn{1}{c}{$\begin{array}{c}\text { Untranslated } \\
\text { exon recovered }\end{array}$} & $\begin{array}{c}\text { Site or } \\
\text { authors }\end{array}$ \\
\hline AB107271 & Adipocyte & A1 (296), E1 & NCBI \\
AB097931 & Adipocyte & A1 (296), E1 & NCBI \\
AL523434 & Neuroblastoma & A0 (160), A2, E1-E6 & NCBI \\
AA298089 & Ovary & A1 (196), A2, E1 & \\
BM924484 & Mix of stomach, & A (287), E1-E2 & NIH \\
& colon and kidney & & \\
BX363320 & Uterine & A0, A2, E1-E5 & NBCI \\
CB133173 & Liver & A5, A2, E1-E2 & NCBI \\
BM744007 & Ascite & A2 (42), E1-E3 & NBCI \\
CN289139 & Stem cell & A5, A2, E1-E2 & (39) \\
AL543579 & Placenta & A0 (119), E1-E6 & NBCI \\
\hline
\end{tabular}

${ }^{a}$ Numbers represent the sequence length in nucleotides of untranslated exon.

and that of the corresponding human genomic sequence. We decided therefore to exclude exon $\mathrm{D}$ from the present study. Likewise, the sequence of exon $\mathrm{C}$ is present in the human PPARG gene. However, using RT-PCR experiments, we did not observe the presence of any transcript including exon $\mathrm{C}$ joined to $\mathrm{E} 1$ neither in human colorectal-derived

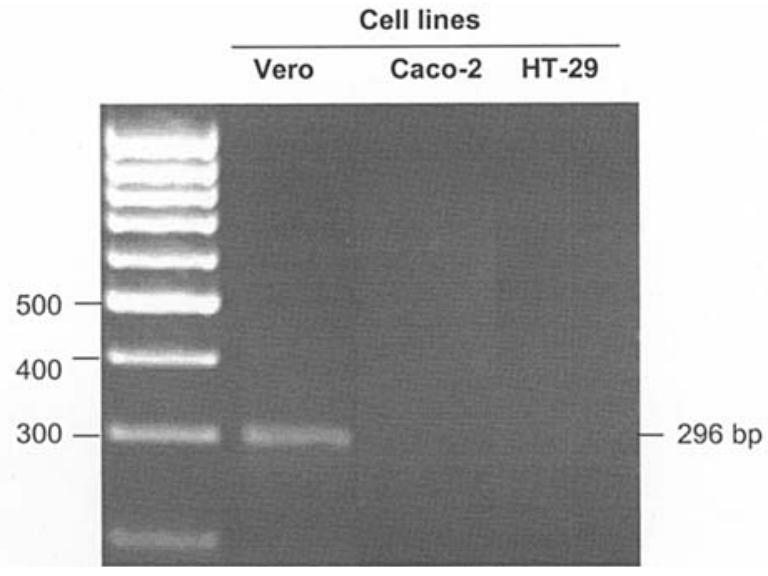

Figure 2. Absence of mRNA containing exon $\mathrm{C}$ in colon-derived cell lines. Total RNA was extracted from 5-day-old Vero, Caco-2 or HT-29 cells. RT-PCR experiments were performed with specific primers designed from exon $\mathrm{C}$ and exon $\mathrm{E} 1$ of the $P P A R G$ gene.

cells (Fig. 2) nor in human colorectal samples (data not shown). In contrast, we amplified the exonic region between exons C and E1 when RT-PCR was performed with total RNA extracted from Vero cells in a control experiment (Fig. 2).

Presence of PPAR protein in colon derived cell lines. PPAR $\gamma$ protein content was quantified in four colon adenocarcinoma cell lines namely Caco-2, HT-29, HCT116 and HT-29 MTX 10-5 M Rev. Upon cell culture, Caco-2 and HT-29 MTX $10^{-5}$ M Rev cells differentiated spontaneously as

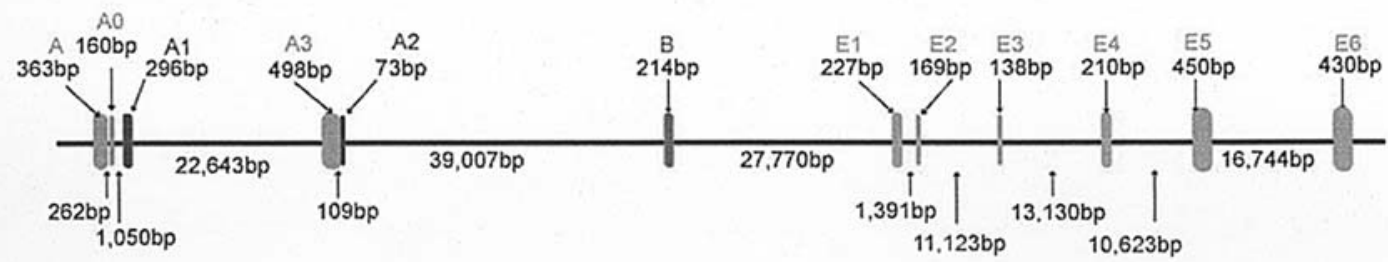

scale : $1 \mathrm{~cm}=5500 \mathrm{bp}$

\section{b}

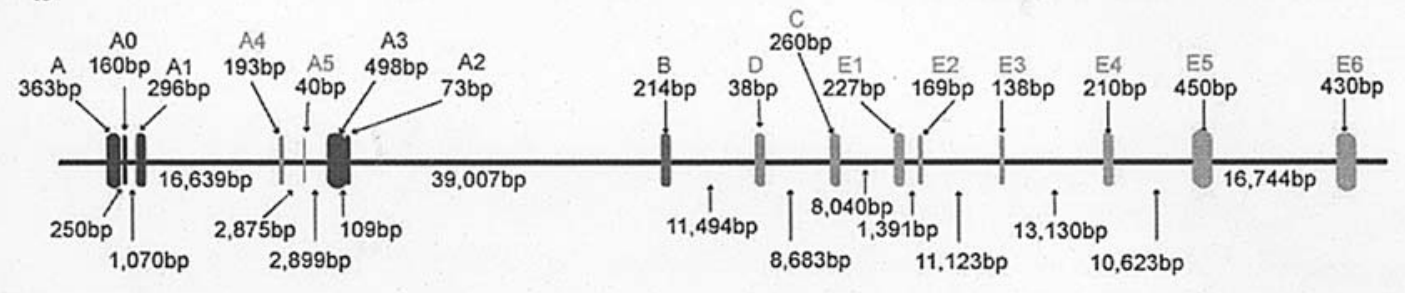

Figure 1. Map of the PPARG gene. (a) Untranslated exons nomenclature is based on published work $(9,10,13-15)$. This scheme (adapted herein) shows $P P A R G$ gene organization presented by Wang et al (14). (b) Predicted organization of the PPARG gene from bioinformatic analysis and completed with reference (14). Lengths of known or putative untranslated exons and introns are given. 


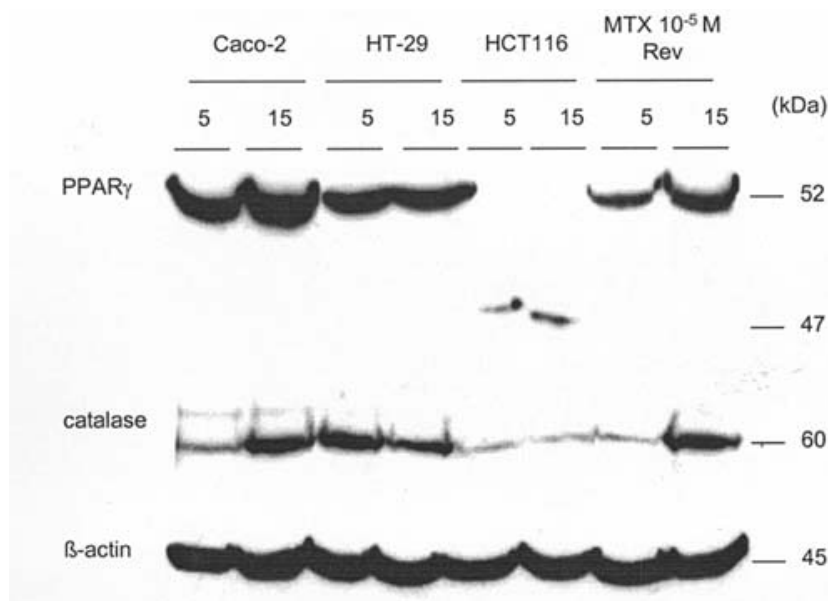

Figure 3. PPAR $\gamma$ protein content in colon-derived cells. Cell homogenates were prepared from 5- and 15-day-old cells. Protein extracts were submitted to Western blotting as described in Materials and methods. Blots were probed with a commercial rabbit polyclonal antibody raised against PPAR $\gamma$. Control experiments for protein loading were performed with a monoclonal antibody raised against B-actin and with Coomassie blue coloration of the PVDF membrane (data not shown). A polyclonal antibody against catalase (17) was used to demonstrate spontaneous differentiation occurring in Caco-2 and HT-29 MTX $10^{-5} \mathrm{M}$ Rev cells. Typical results are from at least three independent experiments. absorptive (24) and mucus-secreting cells (25), respectively. HT-29 and HCT116 cells remained undifferentiated in the same culture delay. As previously shown (26), catalase content used as a marker of differentiation was increased during spontaneous differentiation process occurring in Caco-2 cells, but also in HT-29 MTX 10 $10^{-5} \mathrm{M}$ Rev cells. We demonstrated that PPAR $\gamma$ protein was present in these cells with an estimated $\mathrm{Mr}$ at $50 \mathrm{kDa}$ (Fig. 3). In Caco-2 or HT-29 MTX $10^{-5}$ M Rev homogenates, PPAR $\gamma$ protein content was increased from 5-15 days in culture whereas it decreased in HT-29 during the same culture duration. In HCT 116 cells, PPAR $\gamma$ protein corresponded to a band estimated at $47 \mathrm{kDa}$. The reason for such a difference is not clear. We suggest that PPAR $\gamma$ protein is degraded in this cell line and that the observed band is the result of receptor degradation as previously reported $(7,27)$.

Presence of different PPAR 1 transcripts in colon derived cell lines or from other tissue origins. PPAR $\gamma 1$ mRNA content was quantified by RT-PCR analysis in the selected colon cell lines. As shown in Fig. 4, PPAR $\gamma$ mRNA levels (estimated with primers designed in exon 4 and 6) increased significantly upon culture duration in Caco-2 and HT-29 MTX $10^{-5} \mathrm{M}$

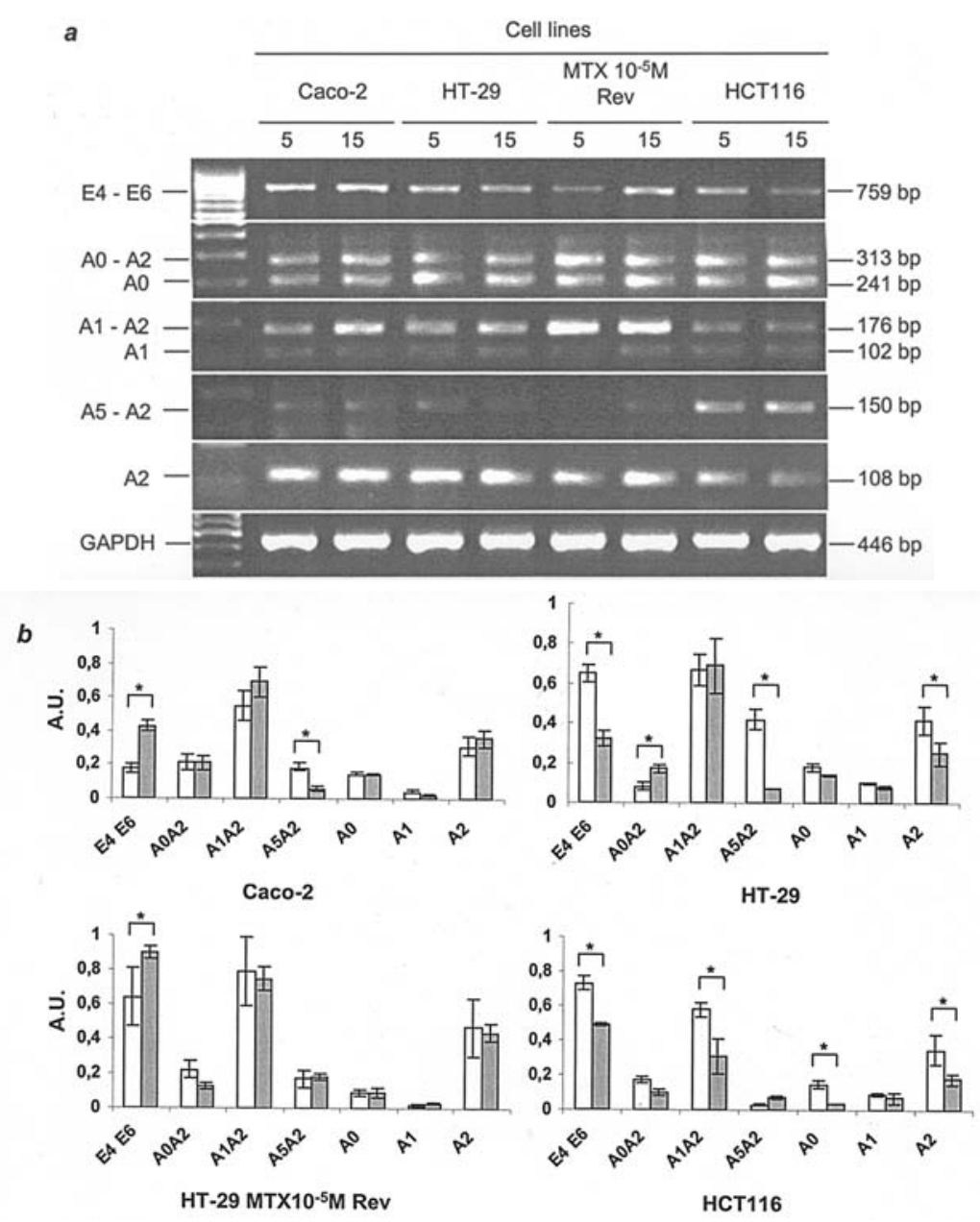

Figure 4. mRNA untranslated exonic region expression in colon cell lines. PolyA ${ }^{+}$mRNAs were prepared from 5- or 15-day-old cells and untranslated exonic regions of PPAR $\gamma 1$ transcripts were quantified by semi-quantitative RT-PCR with specific primers from each exon Ai and exon E1 (Table I) or exon E4 and E6 (a). The amplified regions are named according to the composition of untranslated exon fused to exon E1. The intensities of the bands were quantified and the ratio between intensities of PPAR $\gamma 1$ exonic regions and GAPDH were determined at 5 (white bar) and 15 days (grey bar) (b). The bar graphs represent the mean \pm SD from 3 independent experiments. Significant difference $(*)$ at P-value $<0.05$ (ANOVA) are shown in (b). 


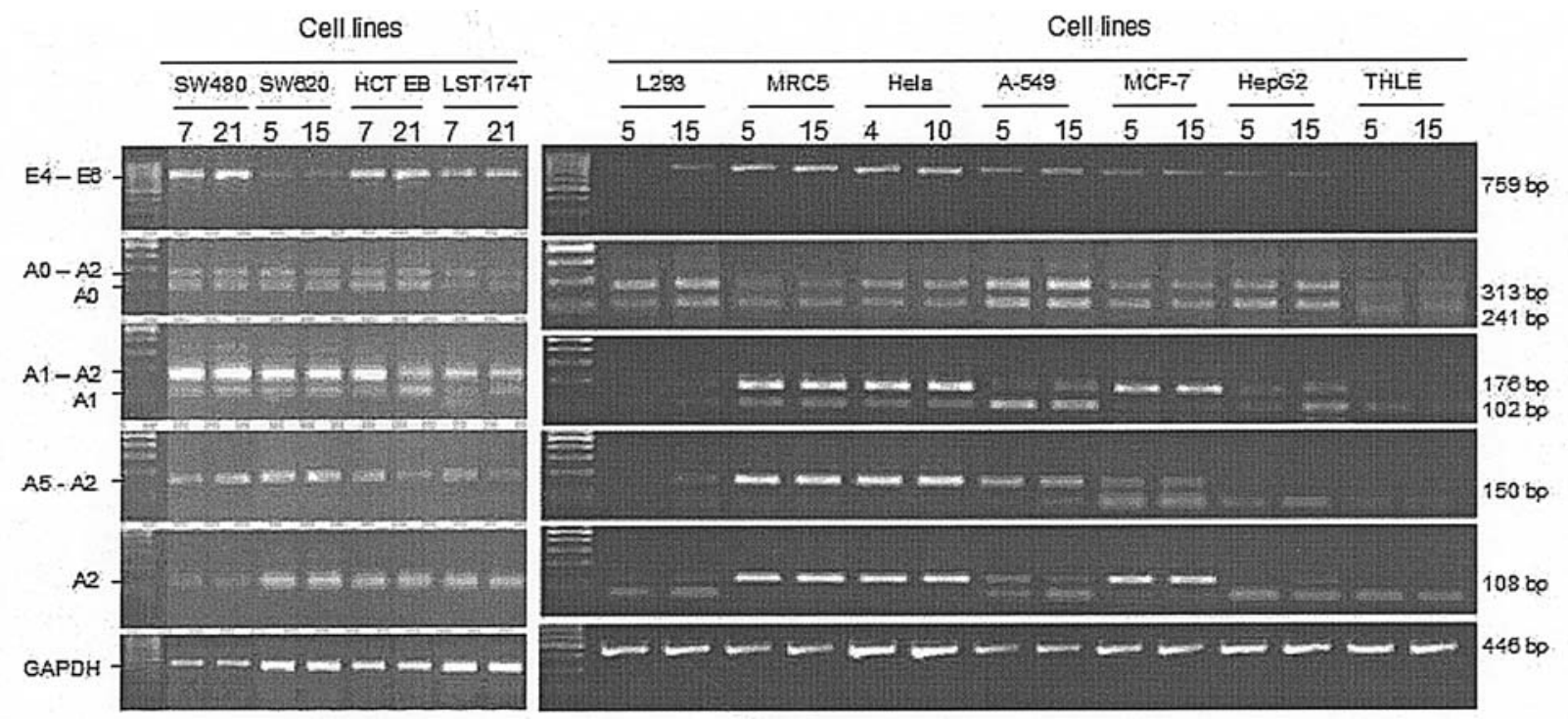

Figure 5. mRNA untranslated exonic region expression in various cell models. Total RNA was prepared from cells harvested during proliferation or stationary culture stage and submitted to RT-PCR with specific primers from each exon Ai and exon E1 or exon E4 and E6. The amplified regions are named according to the composition of untranslated exon linked to exon E1. SW480, SW620, HCT EB and LS 174T are colon adenocarcinoma-derived cell lines. L293 originated from a kidney cell transformed with adenovirus 5 DNA, MRC5 cell line is a fibroblastic-derived cell line, HeLa cells derived from an epidermoid carcinoma, A549 from a lung carcinoma, MCF-7 cells from a breast adenocarcinoma, HepG2 from a hepatocellular carcinoma. THLE cell line was obtained after SV40 large antigen-T immortalization of human hepatocytes (40).
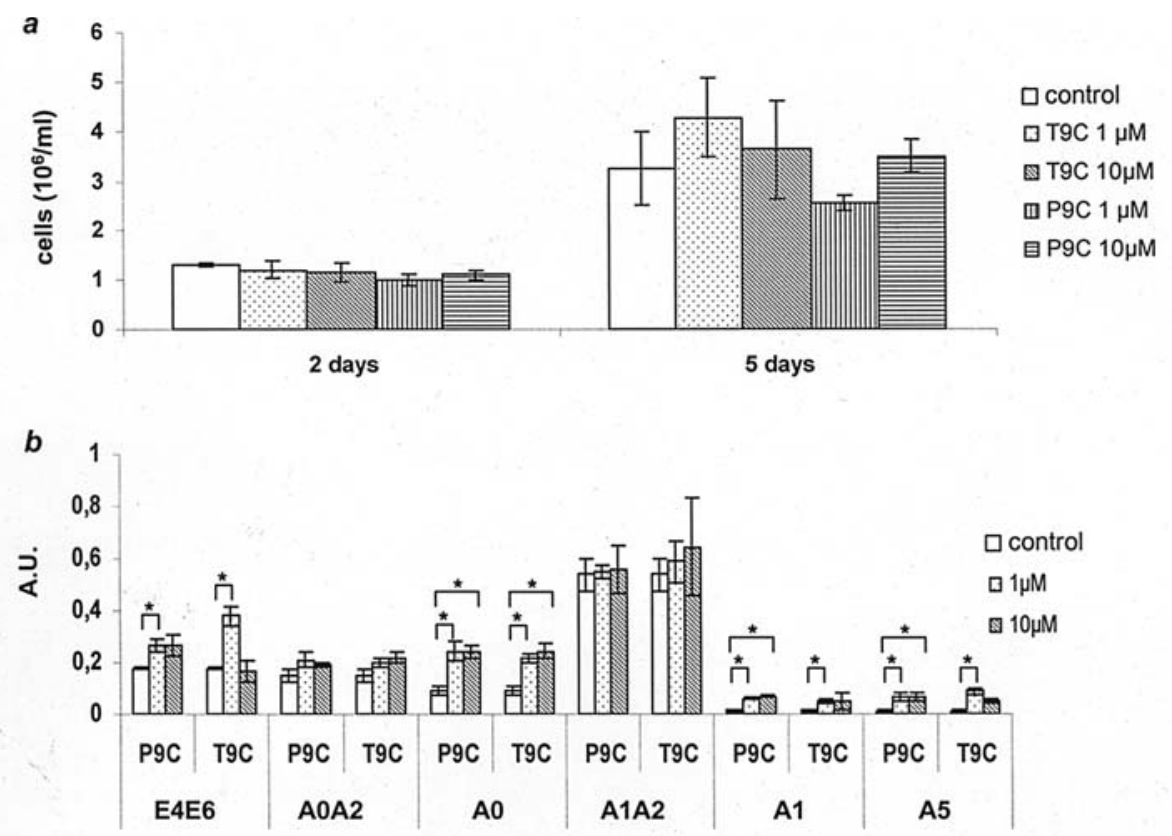

Figure 6. Quantification of PPAR $\gamma 1$ transcripts in HT-29 cells treated with PPAR $\gamma$ agonists. HT-29 cells were treated during 5 days with troglitazone or pioglitazone as indicated. (a) Cell count was carried out with Trypan blue. Cells were numbered at least 4 times for each treatment. (b) Total RNA was extracted from cell layers and submitted to RT-PCR analysis using primers designed in untranslated exon Ai and E1 or in exon E4 and E6. The intensities of the bands were quantified and the ratio between intensities of each PPAR $\gamma 1$ exonic region and GAPDH was calculated. The bar graphs represent the mean \pm SD from 3 independent experiments. Significant differences $(*)$ at P-value $<0.05$ are shown (ANOVA). P9C, T9C: combined treatment respectively with pioglitazone or troglitazone and 9-cis retinoic acid (see Materials and methods).

Rev differentiating cells, whereas they decreased in HT-29 and HCT116 cells. We investigated which transcripts may account for the total level of PPAR $\gamma 1$ mRNA. Several exonic regions were amplified with sense primer designed for each untranslated exon and antisense primer designed for exon E1. Since PPAR $\gamma$ was present in the four cell lines tested, semi-quantification of PPAR $\gamma 1$ transcripts were planed using
polyA $^{+}$RNA prepared from cells cultured for 5 and 15 days (Fig. 4b).

Using exon $\mathrm{A} 0$ or $\mathrm{A} 1$ sense primer and exon $\mathrm{E} 1$ antisense primer (Fig. 4a), two PCR products were obtained with an estimated length of 313 and 241 bp or 176 and 102 bp, respectively. The longest PCR products included exon A2 as demonstrated by digestion of the PCR product with HinfI 

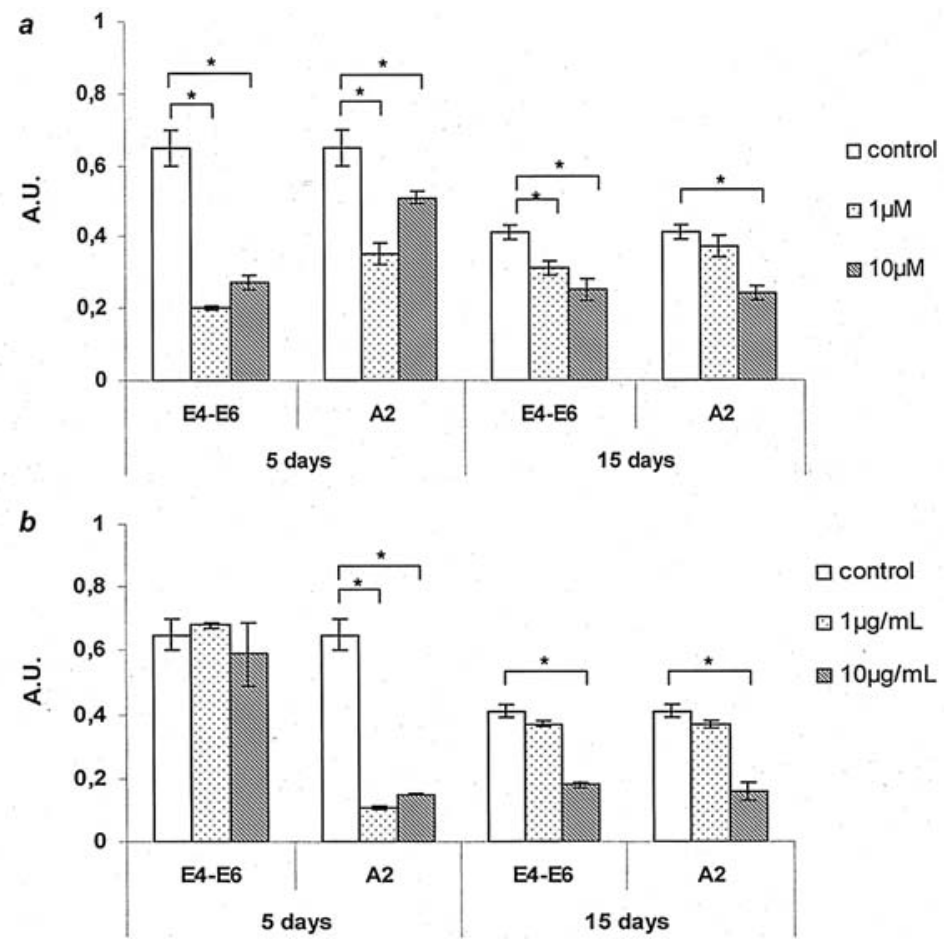

Figure 7. PPAR $\gamma 1$ mRNA levels after drug treatment. Caco-2 and HT-29 cells were cultured during 5 and 15 days and treated with actinomycin D (a) or cycloheximide (b) for $24 \mathrm{~h}$. Total RNA was extracted and submitted to RT-PCR using primers designed in exon E4-E6 and exon A2 and E1, respectively. The intensities of the bands were quantified and the ratios between intensities of each PPAR $\gamma 1$ exonic region and GAPDH were calculated. The bar graphs represent the mean \pm SD from 3 independent experiments. Significant difference $(*)$ at P-value $<0.05$ are shown (ANOVA).

which restriction site is present only in exon A2 (data not shown). Likewise, amplification with sense primer in exon A5 and antisense primer in exon E1 gave a single band estimated at $150 \mathrm{pb}$ which contained exon A2 (Fig. 4a). Amplification was also carried out with sense primer designed in exon A2 (Fig. 4a). The obtained PCR products estimated at $108 \mathrm{bp}$ account for all the mRNA including exon A2 or for the mRNA containing exclusively exon A2 in its 5' UTR, namely PPAR $\gamma 3$ mRNA (10).

Semi-quantification of each exonic region suggested that the transcripts for the so-called PPAR $\gamma 1$ isoform were mainly represented by combination of exons A1-A2-E1-6 as observed previously (9). The other mRNAs containing the untranslated region $\mathrm{A} 0-\mathrm{A} 2, \mathrm{~A} 5-\mathrm{A} 2, \mathrm{~A} 0$ alone or $\mathrm{A} 1$ alone, were less abundant in all colon cell lines tested. However, the relative levels of each mRNA depended on cell line and culture duration. The transcripts containing the A5-A2 region decreased in Caco-2 and HT-29 cells whereas they increased in HCT116 cells (Fig. 4b). Transcripts containing the A0-A2 region decreased in HT-29 MTX 10-5 M Rev cells. Furthermore, each PPAR $\gamma 1$ transcript studied here was recovered in the other cell lines tested but with strong differences in the mRNA levels (Fig. 5). For example, transcripts containing A5 were detected in MRC5 and HeLa cells, but we failed to detect them in HepG2 and THLE cells. PPAR $\gamma 1$ transcripts containing the A1-A2 exonic region (band estimated at $176 \mathrm{bp}$ ) were more abundant in MRC5, HeLa or MCF-7 than in A-549 cells. At least in HepG2, PPAR $\gamma 1$ level was represented mainly by transcripts that contained untranslated exonic region $\mathrm{A} 0-\mathrm{A} 2$ or $\mathrm{A} 0$ alone. In other colorectal cell lines used, higher expression of exonic region A5-A2-E1 was observed in SW480, SW620, HCT EB and LS174T cells (Fig. 5).

Effect of agonist treatment on PPAR 1 mRNA level in HT-29 cells. HT-29 cells were treated with troglitazone or pioglitazone in the presence of 9-cis retinoic acid during the proliferation stage of the cells, in order to investigate possible changes in PPAR $\gamma 1$ transcripts levels (Fig. 6b). Since PPAR $\gamma$ agonists have been shown to block cell growth and to increase cell anoikis, we first counted cell populations during dose- (1 or $10 \mu \mathrm{M}$ agonist and $1 \mu \mathrm{M}$ 9-cis retinoic acid) and time course-treatment (5 days). There were no significant variations in cell counts at whatever the treatment used (Fig. 6a). A significant increase was observed only in PPAR $\gamma$ mRNA content including untranslated exon A1 (3 times), A0 (2 times) or exonic region A5-A2 (5 times). No significant alteration was observed in the mRNA levels of the other transcripts, which included untranslated exon A2 in exonic region A1-A2 and A0-A2 (Fig. 6b).

Effect of actinomycin D and cycloheximide on PPAR 1 mRNA level in HT-29 cells. Since increased PPAR $\gamma$ mRNA levels were observed for transcripts excluding A2 exon (except for the A5-A2 untranslated region), we hypothesised that the presence of A2 untranslated exon may contribute to PPAR $\gamma$ mRNA stability. Therefore, HT-29 cells were cultured for 5 or 15 days, then treated with actinomycin $\mathrm{D}(1$ or $10 \mu \mathrm{M})$ or cycloheximide (1 or $10 \mu \mathrm{g} / \mathrm{ml}$ ) for $24 \mathrm{~h}$ (Fig. 7a and b, respectively). RT-PCR analysis was limited to amplification of E4-E6 and A2-E1 exonic regions. Cells treated with actinomycin $\mathrm{D}$ at 5 days of culture exhibited a $70 \%$ decrease 


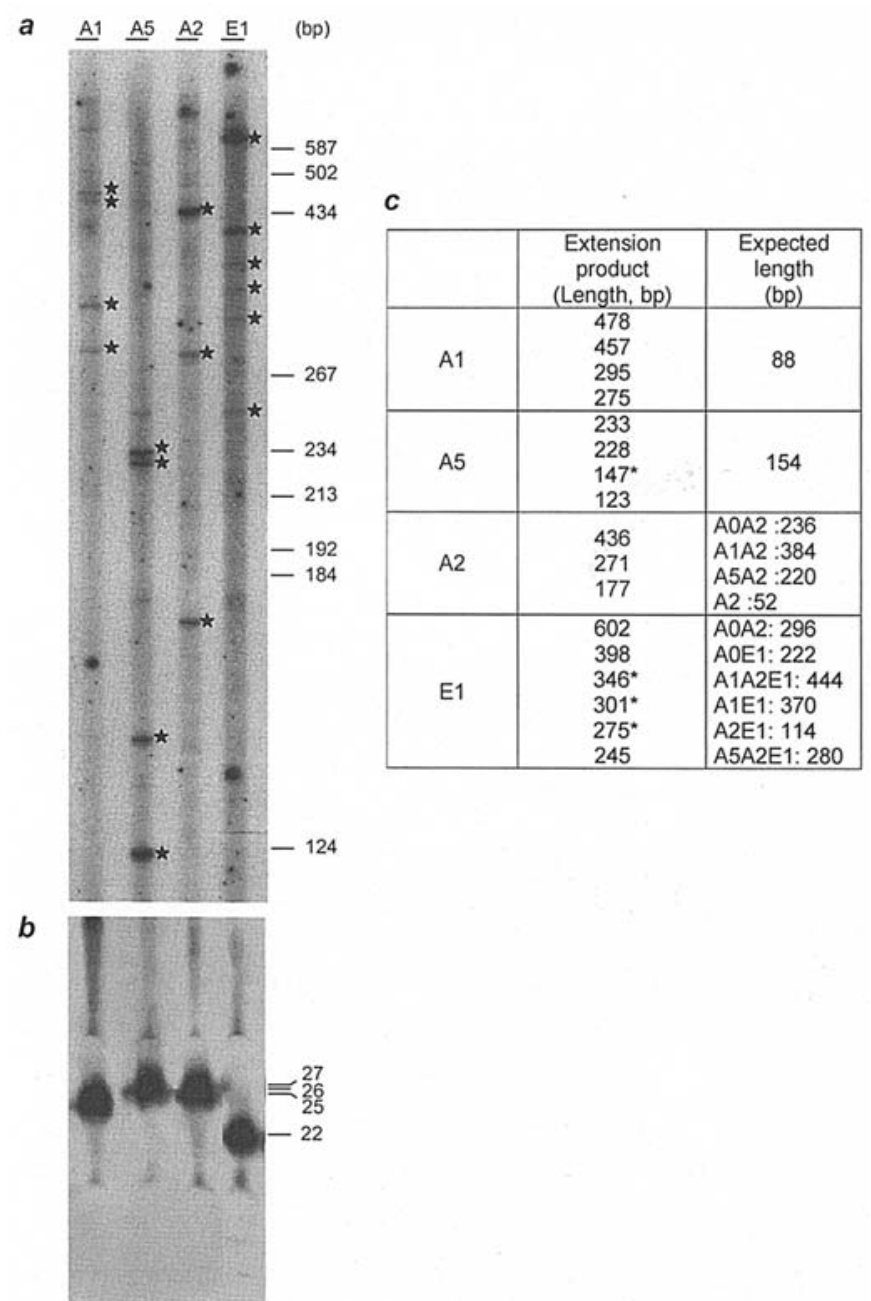

Figure 8. 5' Primer extension products revealed by urea-sequencing gel. 5' Primer extension was carried out as described in Materials and methods with polyA+ RNA prepared from human HT29 adenocarcinoma-derived cells. (a) The extension products are indicated by black stars. (b) Results of free labelled primers are presented. (c) The table summarizes the length of each primer extension product. The known exonic regions recovered by the procedure are indicated by asterisk.

in PPAR $\gamma 1$ initial level estimated with primers designed in exon E4 and E6 (Fig. 7a). Amplification product of the exonic region containing exon $\mathrm{A} 2$ was reduced to $50 \%$. HT-29 cells were less drug-sensitive after 15 days in culture, since mRNA levels were only reduced with high drug concentration (a $40 \%$ decrease). We next treated cells with cycloheximide for $24 \mathrm{~h}$ in order to verify if PPAR $\gamma$ mRNA levels could be altered by inhibition of protein synthesis (Fig. 7b). In 5-day-treated HT-29 cells, no change was found when PPAR $\gamma$ levels were quantified with primers designed in exon E4 and E6. An 85\%-decrease was observed in PPAR $\gamma 1$ mRNA level estimated with primers designed in exon A2 and E1. In contrast, alteration in PPAR $\gamma$ mRNA levels in 15-dayold HT-29 cells was only obtained with high concentrations of cycloheximide (a $60 \%$ decrease). Our results suggested that during the proliferation stage of HT-29 cells, two mechanisms regulate changes in PPAR $\gamma$ transcript levels; firstly, whatever the mechanism, one part of PPAR $\gamma$ transcript seems to be dependent on the presence of de novo protein synthesis.
Secondly, part of the PPAR $\gamma$ transcripts turnover is high as demonstrated by actinomycin $\mathrm{D}$ treatment and quantification with primers designed in exon E4 and E6.

5'-Primer extension. We performed 5' primer extension with poly $\mathrm{A}^{+}$prepared from 15 -day-old adenocarcinoma cells (Fig. 8). As shown in Fig. 8a, we failed to detect extension product corresponding to exon A2 alone (estimated length at $52 \mathrm{bp}$ ). These results contrasted with previous work demonstrating that exon A2 alone constitutes a specific transcript id est PPAR $\gamma 3$ in human cell models (10). Experiments were also extended with antisense primer designed in exon A1, A5 and E1. Surprisingly, several unexpected extension products were obtained starting with A1, A2, A5 and E1 primers. Our results suggested that either unknown exon may exist and participate in the diversity of PPAR $\gamma 1$ transcripts or the lengths of known exons are greater than previously described.

\section{Discussion}

PPAR $\gamma$ has been implicated in colorectal cancer and is thought to exhibit a protective action when the receptor is activated with a specific agonist (28). This protective role has been studied in colorectal cancer-derived cells and results suggest that PPAR $\gamma$ agonist treatments lead to inhibition of cell growth, enhancement of protein markers for differentiation and/or induction of cell apoptotic processes. The agonist effect depends largely on the cell line tested and is dose-dependent (29).

In colon and colorectal cell lines, PPAR $\gamma 1$ is the main protein isoform $(30,31)$. Recently, several transcripts resulting from alternative promoter usage and splicing of untranslated exons of the PPARG gene have been identified (14). Bioinformatic analysis based on previous data $(9,10,13,14)$ and representative EST alignment (Table II) lead us to complete a previous map of known and putative untranslated exons named exon A, A0-A5 (Fig. 1). However, using RT-PCR experiments, we failed to detect A, A3 and A4 and therefore it is likely that these exons are not included in human colon PPAR $\gamma 1$ mRNA. Wang et al demonstrated that exons A and $\mathrm{A} 3$ are used in normal and tumoral mammary tissues (14). Exon A3 expression is restricted to normal mammary tissue suggesting a tissue specific expression. In the present study, similar results have been obtained with exon A5, whose expression is higher in fibroblast or HeLa cells than in colorectal cancer-derived cells (Figs. 5 and 4, respectively). Our results demonstrated that mRNA composed of the exonic region A5-A2 is higher in proliferating cells in three out of four cell-lines tested (Fig. 4b).

In colorectal cancer-derived cells, we showed that several transcripts encoding PPAR $\gamma 1$ protein are present as demonstrated by RT-PCR and by 5 ' primer extension experiments (Figs. 4, 5 and 8). Our results support evidence that PPAR $\gamma 1$ transcription depends on multiple promoter usage and alternative splicing leading to fine transcription regulation within the cells as described within macrophages and breast cancer cells (13-15). Likewise, in pre-adipocytes and in mature adipocytes, PPAR $\gamma 1$ mRNA levels remain constant whereas PPAR $\gamma 2$ mRNA levels increase upon adipocyte differentiation (32-34). When colon cancer-derived 
cells were treated with PPAR $\gamma$ agonists (Fig. 6b), the PPAR $\gamma$ mRNA level was modified only for the combined A0-, A1-, and A5-A2-PPAR $\gamma 1$ transcripts, the levels of the other transcripts remained constant. It must be noted that we used PPAR $\gamma$ agonist concentrations that did not induce cell apoptosis as it has been demonstrated by others $(29,35,36)$. Additional treatments either with actinomycin D (Fig. 7a) or with cycloheximide (Fig. 7b) suggest that PPAR $\gamma$ transcript content depends on RNA flux controlled in two ways, high mRNA turnover and protein synthesis-dependent stability of mRNA. Moreover, we show here that increases in the PPAR $\gamma 1$ mRNA levels in response to receptor agonist treatment were associated with increases in particular transcripts levels (Fig. 6b). Similar results were obtained recently with human THP-1 macrophages (15). Treatment with agonist increased PPAR $\gamma$ transcript isoform composed of particular exon C and D (and named PPAR $\gamma 5$ isoform), whereas agonist treatment leads to decrease PPAR $\gamma 1$ and $\gamma 2$ mRNA levels. We suggested that A2 could participate to structural stability of PPAR $\gamma$ mRNA. Taken together, our results did not confirm previous work demonstrating that PPAR $\gamma 3$ is the main isoform in colon cells models $(26,37)$. Using 5' extension experiment, we failed to demonstrate any extension product at the expected length (at $52 \mathrm{bp}$ ) when experiments were carried out with antisense primer designed in exon A2 (Fig. 8). Likewise, when HT-29 cells were treated with PPAR $\gamma$ agonist at low concentration, no change was observed in the mRNA isoform levels corresponding to the so-called PPAR $\gamma 1$ or PPAR $\gamma 3$ transcripts, as demonstrated by others using oxidized metabolites of linoleic acids as endogenous ligands for PPAR $\gamma$ (37). Others studies are needed to clarify the impact of specific treatment to the expression of each particular PPAR $\gamma 1$ transcript isoform. The role of each PPAR $\gamma 1$ transcript has to be established in colon cell model, even though the implication of the receptor in intestinal cell regulation begins to emerge (5).

Alternative splicing is a crucial mechanism to explain the diversity of gene expression. This mechanism has been shown to be altered in cancer (16). The involvement of PPAR $\gamma$ mRNA diversity had to be stated during development, proliferation or differentiation in the case of colon cells. As demonstrated recently, alternative splicing could explain the diverse modifications observed in signalling pathway from embryonic stem cells to tissue stem cells (38). In the present work, we suggested that alternative splicing could modify the diversity and the levels of PPAR $\gamma$ transcripts. This process could change the transcription rate in response to a specific signalling pathway or by ligand coactivatordependent recruitment, as suggested by Chen et al (15). Finally, using 5' primer extension (Fig. 8) we detected unexpected 5' mRNA regions, which could not be assigned to association of some known exon A1. It is possible that other exonic combinations may exist as demonstrated recently in human THP-1 macrophages (15). It will be of interest to investigate if other untranslated exons may exist or not. In conclusion, we reported that in colon cancerderived cells, diverse transcripts encoding PPAR $\gamma 1$ protein exist due to specific promoter usage and alternative splicing. The respective levels of the transcripts depend on the colon cell model used.

\section{Acknowledgements}

We thank Professor D. Desor for statistical analysis, E. Brunner for technical assistance, Professor S. Thornton for reading the manuscript. This work was supported by grants from 'Ligue contre le Cancer', 'Association pour la Recherche contre le Cancer' and from 'CIRC-CHRU Nancy'.

\section{References}

1. Isseman I and Green S: Activation of a member of the steroid hormone receptor superfamily by peroxisome proliferators. Nature 347: 645-650, 1990

2. Wahli W, Devchand PR, Ijpenberg A, et al: Fatty acids, eicosanoids, and hypolipidemic agents regulate gene expression through direct binding to peroxisome proliferator-activated receptors. Adv Exp Med Biol 447: 199-209, 1999.

3. Kliewer SA, Umesono K, Noonan DJ, et al: Convergence of 9-cis retinoic acid and peroxisome proliferator signalling pathways through heterodimer formation of their receptors. Nature 358: 771-774, 1992.

4. Isseman I, Prince RA, Tugwood JD, et al: The peroxisome proliferator-activated receptor: retinoid $\mathrm{X}$ receptor heterodimer is activated by fatty acids and fibrate hypolipidaemic drugs. J Mol Endocrinol 11: 37-47, 1993

5. Drori S, Girnun G, Tou L, et al: Hic-5 regulates an epithelial program mediated by PPAR $\gamma$. Genes Dev 19: 362-375, 2005.

6. Michalik L, Desvergnes B and Whali W: Peroxisome proliferator-activated receptors and cancer: complex stories. Nat Rev Cancer 4: 61-70, 2004.

7. Beamer BA, Negri C, Yen CJ, et al: Chromosomal localization and partial genomic structure of the human peroxisome proliferator activated receptor-gamma (hPPAR gamma) gene. Biochem Biophys Res Commun 233: 756-759, 1997.

8. Elbrecht A, Chen Y, Cullinan C, et al: Molecular cloning, expression and characterization of human peroxisome proliferator-activated receptors $\gamma 1$ and $\gamma 2$. Biochem Biophys Res Commun 224: 431-437, 1996.

9. Fajas L, Auboeuf D, Raspe E, et al: The organization, promoter analysis, and expression of the human PPAR gamma gene. J Biol Chem 272: 18779-18789, 1997.

10. Fajas L, Fruchart JC and Auwerx J: PPARgamma3 mRNA: a distinct PPARgamma mRNA subtype transcribed from an independent promoter. FEBS Lett 438: 55-60, 1998.

11. Sundvold $\mathrm{H}$ and Lien $\mathrm{S}$ : Identification of a novel peroxisome proliferator-activated receptor (PPAR) $\gamma$ promoter in man and transactivation by the nuclear receptor ROR $\alpha 1$. Biochem Biophys Res Commun 287: 383-390, 2001.

12. Zhu Y, Qi C, Korenberg JR, et al: Structural organization of mouse peroxisome proliferator-activated receptor- $\gamma$ (mPPAR $\gamma)$ gene: alternative promoter use and different splicing yield two mPPAR $\gamma$ isoforms. Proc Natl Acad Sci USA 92: 7921-7925, 1995.

13. Zhou J, Wilson K and Medh J: Genetic analysis of four novel peroxisome proliferator activated receptor $-\gamma$ splice variants in monkey macrophages. Biochem Biophys Res Commun 293: 274-283, 2002.

14. Wang X, Southard C and Kilgore M: The increased expression of peroxisome proliferator-activated receptor- $\gamma 1$ in human breast cancer is mediated by selective promoter usage. Cancer Res 64: 5592-5596, 2004

15. Chen Y, Jimenez A and Medh J: Identification and regulation of novel PPAR $\gamma$-splice variants in human THP-1 macrophages. Biochem Biophys Acta 1759: 32-43, 2006.

16. Kalnina Z, Zahakin P, Silina K, et al: Alteration of pre-mRNA splicing in cancer. Genes Chromosomes Cancer 42: 342-357, 2005.

17. El-Bouhtoury F, Keller JM, Colin S, et al: Peroxisomal enzymes in normal and tumoral human breast. J Pathol 166: 27-35, 1992.

18. Chomczynski $\mathrm{P}$ and Sacchi N: Single-step method of RNA isolation by acid guanidium-thiocyanate-phenol-chloroform extraction. Anal Biochem 162: 156-159, 1987.

19. Aviv $H$ and Leder P: Purification of biologically active globin messager RNA by chromatography on oligo thymidylic acid-cellulose. Proc Natl Acad Sci USA 69: 1408-1412, 1972.

20. Domenjoud L, Nussbaum G, Adham I, et al: Genomic sequences of human protamines whoses gene, PRM1 and PRM2, are clustered. Genomics 8: 127-133, 1990. 
21. Mansen A, Guardioladiaz H, Rafter J, et al: Expression of the peroxisome proliferator-activated receptor (PPAR) in the mouse colonic mucosa. Biochem Biophys Res Commun 222: 844-851, 1996.

22. Laemmli EK: Cleavage of structural proteins during the assembly of the head of bacteriophage T4. Nature 227: 680-685, 1970.

23. Towbin H, Staehelin T and Gordon J: Electrophoretic transfer of proteins from polyacrylamide gels to nitrocellulose sheets: procedure and some applications. Proc Natl Acad Sci USA 76: 4350-4354, 1979.

24. Pinto M, Robine-Leon S, Appay MD, et al: Enterocyte-like differentiation and polarization of the human colon carcinoma cell line Caco-2 in culture. Biol Cell 47: 323-330, 1983.

25. Lesuffleur T, Barbat A, Dussaulx E, et al: Growth adaptation to methotrexate of HT29 human colon carcinoma cells is associated with their ability to differentiate into columnar absorptive and mucus-secreting cells. Cancer Res 50: 6334-6343, 1990.

26. Huin C, Schohn H, Hatier R, et al: Expression of peroxisome proliferator-activated receptors (PPARs) in differentiating human colon adenocarcinoma Caco-2. Biol Cell 94: 15-27, 2002.

27. Hauser S, Adelmant G, Sarraf P, et al: Degradation of the peroxisome proliferator-activated receptor- $\gamma$ is linked to liganddependent activation. J Biol Chem 275: 18527-18533, 2000.

28. Sarraf P, Mueller E, Jones D, et al: Differentiation and reversal of malignant changes in colon cancer through PPARgamma. Nat Med 4: 1046-1052, 1998.

29. Kato M, Kusumi T, Tsuchida S, et al: Induction of differentiation and peroxisome proliferator-activated receptor gamma expression in colon cancer cell lines by troglitazone. J Cancer Res Clin Oncol 130: 73-79, 2004.

30. Auboeuf D, Rieusset J, Fajas L, et al: Tissue distribution and quantification of the expression of peroxisome proliferatoractivated receptors and liver X receptor- $\alpha$ in humans: no alterations in adipose tissue and NIDDM patients. Diabetes 46: 1319-1327, 1997 .
31. Dubois RN, Gupta R, Brockman J, et al: The nuclear eicosanoid receptor, PPARgamma, is aberrantly expressed in colonic cancers. Carcinogenesis 19: 49-53, 1998.

32. Chawla A, Schwartz EJ, Dimaculangan DD, et al: Peroxisome proliferator-activated receptor (PPAR) $\gamma$ : adipose-predominant expression and induction early in adipocyte differentiation. Endocrinology 135: 798-800, 1994.

33. Tontonoz P, Hu E and Spiegelman BM: Stimulation of adipogenesis in fibroblasts by PPAR $\gamma 2$, a lipid-activated transcription factor. Cell 79: 1147-1156, 1994.

34. Thuillier P, Baillie R, Sha X, et al: Cytosolic and nuclear distribution of PPARgamma2 in differentiating 3T3-L1 preadipocytes. J Lipid Res 39: 2329-2338, 1999.

35. Sunami E, Tsuno NH, Kitayama J, et al: Decreased synthesis of matrix metalloproteinase-7 and adhesion to extracellular matrix proteins of human colon cancer cells treated with troglitazone. Surg Today 32: 343-350, 2002.

36. Kitamura S, Miyazaki Y, Shinomura Y, et al: Peroxisome proliferator-activated receptor $\gamma$ induces growth arrest and differentiation of human colon cancer cells. Jpn J Cancer Res 90: 75-80, 1999 .

37. Bull A, Steffensen K, Leers J, et al: Activation of PPAR $\gamma$ in colon tumor cell lines by oxidized metabolites of linoleic acid, endogenous ligands for PPAR $\gamma$. Carcinogenesis 24: 1717-1722, 2003.

38. Pritsker M, Doniger T, Kramer L, et al: Diversification of stem cell molecular repertoire by alternative splicing. Proc Natl Acad Sci USA 102: 14290-14296, 2005.

39. Brandenberger R, Wei H, Zhang S, et al: Transcriptome characterization elucidates signaling networks that control human ES cell growth and differentiation. Nat Biotechnol 22: 707-716, 2004.

40. Pfeifer AM, Cole KE, Smoot DT, et al: Simian virus 40 large tumor antigen-immortalized normal human liver epithelial cells express hepatocyte characteristics and metabolize chemical carcinogens. Proc Natl Acad Sci USA 90: 5123-5127, 1992. 